\title{
Quality Assured Health Care in Certified Breast Centers and Improvement of the Prognosis of Breast Cancer Patients
}

\author{
Matthias W. Beckmann ${ }^{a, b, g *}$ Cosima Brucker ${ }^{c, g *}$ Volker Hanf ${ }^{d *}$ Claudia Rauh $^{a}$ \\ Mayada R. Bani ${ }^{\mathrm{a}}$ Stefanie Knob ${ }^{\mathrm{d}}$ Sabrina Petsch ${ }^{\mathrm{b}}$ Stefan Schick ${ }^{\mathrm{b}}$ \\ Peter A. Fasching ${ }^{a, e, g} \quad$ Arndt Hartmann ${ }^{f, g}$ Michael P. Lux ${ }^{a} \quad$ Lothar Häberle $^{a, b}$ \\ aUniversity Breast Center Franconia, Department of Gynecology and Obstetrics, University Hospital Erlangen, \\ ${ }^{b}$ Clinical Cancer Registry, Tumor Center of the Friedrich Alexander University, Erlangen-Nuremberg, \\ ${ }^{\mathrm{c} B r e a s t}$ Center, Klinikum Nuremberg, ${ }^{\mathrm{d} B r e a s t}$ Center, Klinikum Fuerth, Germany

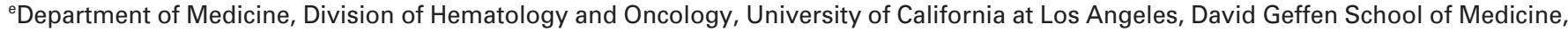 \\ Los Angeles, CA, USA \\ fUniversity Breast Center Franconia, Institute of Pathology, University Hospital Erlangen, \\ ${ }^{9}$ Comprehensive Cancer Center Erlangen-Nuremberg, Friedrich-Alexander University Erlangen-Nuremberg, Germany
}

\section{Keywords}

Breast center - Quality assured health care · Certification . Prognosis · Survival

\section{Summary}

Background: Increasing effort has been put in the implementation and certification of breast centers in order to establish standardized, quality assured health care for breast cancer patients. The aim of this analysis was to investigate whether patients treated in certified breast centers (CBC) have a favorable prognosis as compared to patients treated outside of certified breast treatment units. Patients and Methods: The data of 3,940 patients with invasive nonmetastatic breast cancer were analyzed with regard to differences in patient and tumor characteristics and crude overall survival according to diagnosis in or outside $C B C$ in Middle Franconia, Germany. Patient, tumor, and follow-up data were obtained from the clinical cancer registry. Results: Patients in CBC were younger, and had lower disease stages and lower grading. Independent of the effects of these variables on overall survival, being treated at a $\mathrm{CBC}$ added to the prediction of overall survival. Patients treated at a $\mathrm{CBC}$ had a hazard ratio of 0.70 (95\% confidence interval 0.52-0.93) in the adjusted Cox model. Conclusions: Independent from common prognostic factors, diagnosis and treatment of breast cancer at a $\mathrm{CBC}$ improves the prognosis of patients. It can be hypothesized that this effect is mediated through quality assured health care provided by the certification process.

*These authors contributed equally to this manuscript.

\section{Schlüsselwörter}

Brustzentrum · Qualitätsgesicherte Versorgung · Zertifizierung · Prognose · Überleben

\section{Zusammenfassung}

Hintergrund: In den vergangenen Jahren wurde die Etablierung von zertifizierten Brustzentren vorangetrieben, um eine standardisierte und qualitätsgesicherte Versorgung von Patientinnen mit einem Mammakarzinom zu gewährleisten. Die vorliegende Arbeit untersucht, ob Patientinnen mit einer Behandlung in einem zertifizierten Brustzentrum eine unterschiedliche Prognose im Vergleich zur Versorgung außerhalb zertifizierter Strukturen aufweisen. Patienten und Methoden: Die Daten von 3940 Patientinnen mit einem primären, nicht metastasierten Mammakarzinom des klinischen Krebsregisters Mittelfrankens wurden in Bezug auf anamnestische Faktoren, Tumorcharakteristika und Ergebnisqualität untersucht und mit der Versorgung in und außerhalb zertifizierter Brustzentren korreliert. Ergebnisse: Patientinnen im zertifizierten Brustzentrum waren jünger und hatten ein niedrigeres Tumorstadium und Grading. Unabhängig dieser Variablen hatte die Versorgung durch zertifizierte Brustzentren in einem adjustierten Cox-Modell einen signifikanten positiven Einfluss auf das Gesamtüberleben [Hazard Ratio 0,70 (95\% Konfidenzintervall 0,52$0,93)$ ]. Schlussfolgerungen: Die Versorgung in einem zertifizierten Brustzentrum zeigt unabhängig von den klassischen Prognosefaktoren eine Verbesserung der Prognose von Mammakarzinompatientinnen. Dieses könnte durch die qualitätsgesicherten Versorgung basierend auf dem Zertifizierungsprozess erklärt werden.

\section{KARGER \\ Fax +497614520714 \\ Information@Karger.de}

www.karger.com
(C) 2011 S. Karger GmbH, Freiburg 0378-584X/11/0347-0362\$38.00/0

Accessible online at: www.karger.com/onk
Prof. Dr. med. Matthias W. Beckmann

Friedrich-Alexander-Universität Erlangen-Nürnberg Frauenklinik

Universitätsstraße 21-23, 91054 Erlangen, Germany

fk-direktion@uk-erlangen.de 


\section{Introduction}

The reduction of recurrence rates and the improvement of quality of life are the main aims for any cancer therapy. To reach this goal, the efforts of the last decades did not only aim at the improvement of therapy modalities but also at the improvement of the delivery of health care. The implementation of therapeutic or diagnostic improvements is dependent on the acceptance of clinical trial results by the scientific community and the regulations of responsible authorities. The implementation of quality assured health care according to current therapy standards however seems to be a more complex task and has only recently, over the last decade, found its way into the focus of research, politics, health care providers, and patients.

For breast cancer treatment it has been shown that even after the publication of nationwide guidelines or international therapy recommendations [1-5], the implementation of and adherence to quality assured patient healthcare following these guidelines and recommendations might be unsatisfactory. It is reported that more than $40 \%$ of all patients might not be treated according to guidelines [6] and up to $70 \%$ of breast cancer patients do not get sufficient follow-up care after a diagnosis of breast cancer [7]. The reasons for this lack of guideline adherence are complex and mostly unexplored. Influencing factors might include the provision of a sufficient medical infrastructure, sufficiently educated physicians and patients, a functional network of hospitals with the surrounding screening programs and practicing physicians, and the organization of a breast center with standardized diagnostic and therapeutic pathways for breast cancer patients, including a comprehensive interdisciplinary communication between radiologists, surgeons, oncologists, and pathologists.

In Germany, the quality controlled health care for breast cancer patients has been implemented on several, partially independent, levels. Since 2003, the German Cancer Society (Deutsche Krebsgesellschaft e.V.) together with the German Society for Mastology (Deutsche Gesellschaft für Senologie e.V.) have established a multistep certification process for breast centers with the on site audition of breast centers and the mandatory data collection and analysis on several quality markers and actual follow-up and survival data for each breast cancer patient. This certification process is thought to control the correct implementation of national guidelines and international treatment recommendations as well as safeguarding the correct documentation of these processes. Federal and state authorities additionally request original data on the treatment of patients with breast diseases [8]. Furthermore, some of the breast centers have taken part in the voluntary certification by the European Society for Mastology (EUSOMA) [9, 10].

Since 2009 , it is assumed that about $77 \%$ of all breast cancer patients are treated in breast centers certified by the German Cancer Society [11]. The development and maintenance of these structures are costly and time intensive, albeit no reimbursement for these costs is provided. Up to now, there is very little proof that the efforts truly result in an improved survival or quality of life for breast cancer patients. A reasonable amount of data has been accumulated on the quality indicators that must be interpreted as surrogate markers for the ultimate aims of survival and quality of life [12]. Some of the quality indicators have been linked to improved survival such as the number of breast cancer cases treated per hospital (reviewed by Scharl and Gohring [13]). It is thought that a higher number of treated patients leads to better survival due to superior organization and training of health care professionals. Others studies report improved survival for patients who are treated according to guidelines as compared to those who are not $[6,14,15]$. Based on these facts, it could be hypothesized that patients who are treated in certified breast centers (CBC) might have a better prognosis than patients who are not. The aim of this study was therefore to test this hypothesis in a defined region of Northern Bavaria ('Middle Franconia'), Germany. Hospitals in this area are provided with a public clinical cancer registry regardless of whether they are $\mathrm{CBC}$ or not.

\section{Patients and Methods}

\section{Patient Selection}

Patients with a diagnosis of invasive breast cancer, who were diagnosed between June 2004 and March 2008 and who were registered and documented in the clinical cancer registry for the region of Middle Franconia, were included in this analysis. Cancer registration in Bavaria is based on a state law which combines voluntary reporting of cancer cases to the registry by physicians, dentists and pathologists, compulsory information of patients about their individual registration, and the right of patients to revoke their individual registration at any time. It is anticipated that with regard to breast cancer more than $95 \%$ of all breast cancer cases are reported to the cancer registry for Middle Franconia [16]. Breast cancer cases are reported by CBC as well as non-certified units.

Inclusion requirements for patients for this analysis were: age 18 years or older and diagnosis of invasive breast cancer, no distant metastatic disease, and no prior breast cancer diagnosis. A set requirement for the $\mathrm{CBC}$ was the provision of a mean follow-up of at least 1 year. Three breast centers in the region fulfilled these requirements at the timepoint of the analysis. Additionally, 18 hospitals and practices reported and treated breast cancer patients at the same time as well. Patients were classified into the 2 categories: primary diagnosis and treatment in a CBC vs. diagnosis or treatment outside of a CBC. A total of 3,940 breast cancer patients were registered in the cancer registry, 1,988 of whom were treated in the 3 CBCs and 1,952 in non-certified breast units.

\section{Patient and Tumor Characteristics and Follow-Up}

Patient and tumor characteristics were assessed by reporting breast units and were not centrally reviewed. Data included in this report are age at diagnosis, tumor size categorized into the 4 categories according to the UICC classification (pT) [17], nodal status, and grading. Follow-up data were provided by the treating breast units and participating physicians in Middle Franconia. Additionally, life status was obtained systematically on an annual basis from the local authorities (including the death registry) up to March 2008, after which the database was closed for this analysis. 
Only crude overall survival was available for all breast cancer patients regardless of whether they had been treated in a CBC or not.

\section{Statistical Methods}

Data are presented as means \pm standard deviation (SD) or as frequencies and percentages, unless otherwise noted. Descriptive statistics are provided for the most important clinical parameters including patients' age at diagnosis, tumor size classification (pT1-4), nodal status (positive or negative), and grading. Patients were classified according to 'diagnosed and treated in a $\mathrm{CBC}$ (CBC patients)' vs. 'diagnosed or treated outside of a CBC (non-CBC patients)'. The characteristics of $\mathrm{CBC}$ patients and non-CBC patients were compared using appropriate two-sample statistical tests. Student's t-test was used for continuous characteristics (age), the chi-square test for categorical characteristics (nodal status) and the Wilcoxon rank-sum test for ordinal categorical characteristics (pT and grading).

The main aim was the crude overall survival analysis. The survival time of a patient ranged from the date of diagnosis to either the patient's death or the date of censoring. For patients who were alive at the end of the observation period, survival time is censored at this time. For patients whose life status is unknown at the end of the observation period survival time is censored at the time of the last known follow-up. Cox proportional hazards $(\mathrm{PH})$ models were used to analyze overall survival. The full Cox PH model contained CBC status and the prognostic factors age, tumor size classification, nodal status and grading, and for each of these prognostic factors, the interaction with $\mathrm{CBC}$ status. Backward stepwise variable selection was carried out to obtain the best prognostic model (the final model) with respect to the Akaike information criterion Hazard ratios (HR) for this final model are provided. The clinical parameters were included into the model to ensure that a possible influence of the factor $\mathrm{CBC}$ patients vs. non-CBC patients cannot be explained by these variables. The PH assumptions were checked by tests which correlate scaled Schoenfeld residuals with a suitable transformation of time. All of the tests were two-sided, and a $\mathrm{p}$ value $<0.05$ was regarded as statistically significant. Calculations were carried out using the $\mathrm{R}$ system for statistical computing (version 2.11.1; R Development Core Team, Vienna, Austria, 2010).

\section{Results}

A total of 3,940 patients from 21 treatment units $(3 \mathrm{CBC}$ and 18 non-CBC) were included in this study. Patients were 61.8 $( \pm 13.2)$ years of age and showed typical breast cancer characteristics (table 1). Most of the patients (52.0\%) showed a tumor smaller than $2 \mathrm{~cm}(\mathrm{n}=2,002)$, were node-negative $(63.7 \% ; n=2,429)$, and had grade 2 or 3 tumors (42.6 and $50.2 \%$, respectively).

Comparing patient and tumor characteristics between the $\mathrm{CBC}$ patients and the non-CBC patients, there were statistically significant differences concerning age, tumor size classification, and grading. The differences however did not seem to be substantial. Patients treated in CBC showed a pT1 tumor in $56 \%$ of the cases as compared to $48 \%$ in the group of non-CBC patients ( $\mathrm{p}<0.00001)$; they were on average 2 years younger $(60.6$ vs. 62.9 years; $\mathrm{p}<0.00001)$ and had a higher grading as assessed by the local pathologist $(\mathrm{p}<0.00001)$. Nodal status did not differ significantly between the 2 groups. Median follow-up time in the cohort of CBC patients was 1.5 years compared to 1.9 years in the cohort of non-CBC patients.

For the assessment of the effect on crude overall survival, a Cox PH model was built with stepwise reverse variable selection (table 2). All above mentioned parameters except for grading remained in the final model, revealing their ability to independently contribute to the prediction of crude overall survival. Tumor size classification showed an increasing risk of death with larger tumor size. Patients with a pT2, pT3 or pT4 tumor had a HR of 1.46 (95\% confidence interval (CI) 1.05-2.03), 2.63 (95\% CI 1.56-4.42), and 2.94 (95\% CI 1.87$4.63)$, respectively. Patients with involved lymph nodes showed a HR of 1.82 (95\% CI 1.35-2.45) compared to patients with no involved axillary nodes. Finally in this adjusted Cox $\mathrm{PH}$ model, the status of whether a patient was treated in a $\mathrm{CBC}$ had additional value to predict overall survival. Patients treated in a $\mathrm{CBC}$ had a HR for overall survival of 0.70 (95\% CI 0.52-0.93; $\mathrm{p}=0.01$ ). An alternative Cox PH model that did not include clinical parameters as adjustment variables but as strata, confirmed this result with a HR of 0.69 (95\% CI 0.51-0.92; $\mathrm{p}=0.01$ ). The final model did not include any interactions with $\mathrm{CBC}$ status, i.e. the $\mathrm{HR}$ for $\mathrm{CBC}$ status holds for all analyzed patient characteristics. Since the $\mathrm{PH}$ assumptions are fulfilled (i.e. low correlations of Schoenfeld residuals and time), the HRs are indeed valid throughout the

Table 1. Patient characteristics

\begin{tabular}{lllll}
\hline & All patients & CBC patients & Non-CBC patients & p \\
\hline $\begin{array}{l}\text { Mean age, years (SD) } \\
\text { pT, n (\%) }\end{array}$ & $61.8( \pm 13.2)$ & $60.6( \pm 12.6)$ & $62.9( \pm 13.7)$ & $<0.00001$ \\
pT1 & & & \\
pT2 & $2,002(52.0)$ & $1,094(55.6)$ & $908(48.1)$ & \\
pT3 & $1,509(39.2)$ & $733(37.3)$ & $776(41.1)$ & \\
pT4 & $150(3.9)$ & $68(3.5)$ & $121(6.4)$ & \\
pN, n (\%) & $192(5.0)$ & $71(3.6)$ & $1,171(63.4)$ & 0.00001 \\
Negative & & $1,258(63.9)$ & \\
Positive & $2,429(63.7)$ & $712(36.1)$ & \\
Grading, n (\%) & $1,387(36.3)$ & & & \\
1 & & $199(10.0)$ & $86(4.4)$ & \\
2 & $285(7.2)$ & $955(48.0)$ & $723(37.0)$ & \\
3 & $1,678(42.6)$ & $834(42.0)$ & $1,143(58.6)$ & \\
\hline
\end{tabular}

$\mathrm{CBC}=$ Certified breast center; $\mathrm{SD}=$ standard deviation; $\mathrm{pT}=$ UICC tumor size classification; $\mathrm{pN}=$ axillary lymph node status. 
Table 2. Final Cox proportional hazards model for crude overall survival (pT: tumor size classification according to UICC, $\mathrm{pN}$ : axillary lymph node status, HR: hazard ratio, CI: confidence interval; $\mathrm{CBC}$ : Certified Breast Center)

\begin{tabular}{llll}
\hline & HR & $95 \%$ CI & $\mathrm{p}$ \\
\hline $\begin{array}{l}\text { CBC patient } \\
\quad \text { No }\end{array}$ & 1.00 & & \\
$\quad$ Yes & 0.70 & $(0.52-0.93)$ & 0.01 \\
$\begin{array}{l}\text { Age, years } \\
\leq 50\end{array}$ & 1.00 & & \\
$\quad 51-62$ & 1.07 & $(0.60-1.91)$ & 0.82 \\
63-70 & 1.88 & $(1.14-3.08)$ & 0.01 \\
$\quad \geq 71$ & 4.91 & $(3.12-7.74)$ & $<0.00001$ \\
pT & & & \\
pT1 & 1.00 & & \\
pT2 & 1.46 & $(1.05-2.03)$ & 0.02 \\
pT3 & 2.63 & $(1.56-4.42)$ & $<0.001$ \\
pT4 & 2.94 & $(1.87-4.63)$ & $<0.00001$ \\
pN & & & \\
$\quad$ Negative & 1.00 & & \\
$\quad$ Positive & 1.82 & $(1.35-2.45)$ & $<0.0001$ \\
\hline
\end{tabular}

$\mathrm{HR}=$ Hazard ratio CI $=$ confidence interval $; \mathrm{CBC}=$ certified breast center; $\mathrm{pT}=\mathrm{UICC}$ tumor size classification; $\mathrm{pN}=$ axillary lymph node status.

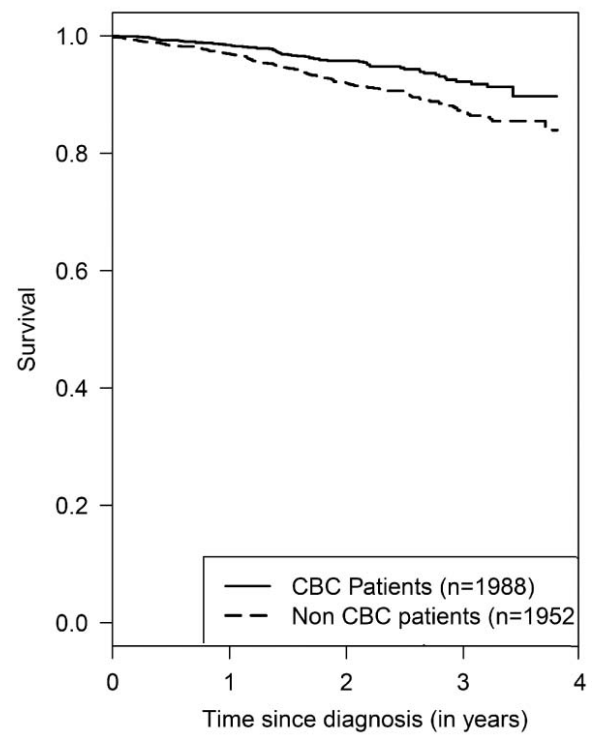

Fig. 1. Kaplan Meier curves for the factor certified breast center (CBC) patients vs. non-CBC patients (adjusted hazard ratio: non-CBC patients: 1 (reference), CBC patients: 0.70 ( $95 \%$ confidence interval 0.52-0.93)).

follow-up time. The final model with additional predictor grading, which had turned out to be non-significant during the variable selection process, yields similar results (data not shown). Kaplan Meier curves for the comparison between $\mathrm{CBC}$ and non-CBC patients are provided in figure 1.

\section{Discussion}

We were able to show that the information of whether a breast cancer patient had been diagnosed and treated in a $\mathrm{CBC}$ as opposed to a non-certified unit contributed to the prediction of crude overall survival as an independent prog- nostic factor when adjusting for common prognostic factors such as age, tumor size, nodal status, and grading. Our data show an effect that was desired when guidelines and the certification process and control of quality assured health care for breast cancer patients were implemented in Germany. There are some studies from Germany that do not compare patients within $\mathrm{CBC}$ with those treated outside $\mathrm{CBC}$, but which access detailed information about the diagnosis and treatment of breast cancer in a cohort of patients and classify the patients as having or not having been treated according to therapy guidelines. Patients who have been treated completely according to therapy guidelines did show the best overall and recurrence-free survival, whereas patients who have not been treated according to guidelines had a higher risk for death $(\mathrm{HR}=2.6 ; 95 \%$ CI 2.0-3.4) and recurrence $(\mathrm{HR}=2.2 ; 95 \%$ CI 1.7-2.8) [6, 14]. Another study from Korea likewise found that compliance with consensus recommendations was significantly associated with better survival [18]. For other cancers such as colorectal cancer and lung cancer a correlation between compliance with cancer care standards and prognosis could be shown as well $[19,20]$.

\section{Limitations}

A similar discussion exists about the effect of the participation in clinical trials on prognosis, providing insight into the limitations concerning the general interpretation of our results. There are meta-analyses and structural reviews reporting on improved outcome of patients within clinical trials vs. those who had not been treated in clinical trials [21-23]. These results even lead to the recommendation that $\mathrm{CBC}$ should treat more than $20 \%$ of their patients in clinical trials. However, other reports did not conclude that enrolment in clinical trials leads to improved outcomes in cancer patients [24]. The discussion of these results includes possible explanations for the effect seen in our study and also other studies that reported on an improved outcome through guideline adherence. Table 3 summarizes these effects. The desired effect would be a systematic treatment effect that results in better quality of breast cancer patient care, mediated through more accurate surgery, and higher percentages of correctly treated patients with regard to radiation and systemic therapy. We cannot compare these figures for our study, because non-CBC breast units usually do not document these features.

Furthermore, there could be an incidental treatment effect that cannot be specified at this point and is purely due to chance. In observational studies, an effect has been described which is referred to as the Hawthorne effect [25], whereby patients who take part in observational studies could start to show a different behavioral pattern. Similarly, patients treated in breast centers could start to show altered behavior. Actually, it has already been reported that patients who attend CBC have an a priori better status of information about breast cancer and have different expectations concerning the quality of care [26]. 
Table 3. Possible effects explaining differences in prognosis and explanation models for the effects found

\begin{tabular}{ll}
\hline Denomination & Description \\
\hline Systematic treatment effect & $\begin{array}{l}\text { altered balance of main treatments of differing efficacy } \\
\text { (CBC vs. non-CBC patients) } \\
\text { Incidental treatment effect }\end{array}$ \\
Hawthorne analogue effect in incidental aspects of treatment or care; effect is \\
$\begin{array}{l}\text { purely due to chance (CBC vs. non-CBC patients) } \\
\text { changes in patients' or clinicians' behavior (other than assumed } \\
\text { by chance) due to being in a CBC, other than expected aspects } \\
\text { (CBC vs. non-CBC patients / CBC vs. non-CBC physicians) } \\
\text { different standards in the measurement of outcome concerning } \\
\text { the study aim }\end{array}$ \\
Detection bias
\end{tabular}

In addition to these more behavioral effects, there could be simple bias effects that could have an influence on the different survival seen in the 2 groups. A general selection bias is unlikely, because all breast cancer patients in a certain area (population-based) have been included in this analysis. However, it could be hypothesized that patients with more advanced disease could more likely be referred to a CBC. This effect would lead to a group of patients that have a more unfavorable prognosis in $\mathrm{CBC}$ and thus support the interpretation that patients in breast centers receive better therapy. However, the tumor size of the CBC patients in our study was smaller and the grading more favorable. A detection bias, i.e. differences in the methodology of the assessment of outcome measures, could have had an influence in our study. Followup information is provided by the breast cancer treating units, and $\mathrm{CBC}$ have to report outcome, whereas non-CBC do not have to provide these data during an audit. Therefore, there could be a difference in the standards of measurement of survival as an outcome variable.

Apart from the above discussed limitations, a point of criticism could be that only information on age, tumor size, nodal status, and grading have been included in our adjusted Cox regression analyses. Other validated and generally accepted prognostic factors (hormone receptor status, HER2/neu status) were not included. Particularly treatment information was not available for our analysis.
In summary, we were able to show that the information about diagnosis and treatment taking place in a CBC contributed to the prediction of overall survival as an independent prognostic factor in addition to the variables tumor size, age, grading, and nodal status. It can be hypothesized that this effect might be the result of quality assured health care, implemented and controlled by the certification process. How this improvement is effectively mediated, is a matter of speculation. The likely explanation is the adherence to a guidelineconform therapy and follow-up care. However, the limitation of our study design warrant further investigation of this finding in order to exclude behavioral and bias effects.

\section{Disclosure Statement}

There are no conflicts of interest.

\section{Acknowledgement}

This work is a collaborative effort of a network of certified breast centers and the practicing physicians that are mandatory part of a certified breast center. Furthermore all pathology departments in the region of Middle Franconia take part in the clinical cancer registry and have to be thanked as well.

\section{References}

1 NCCN: NCCN Guideline update: Breast Cancer Version 1.2004. J Natl Compr Canc Netw 2004 2:183-184.

2 Bevers TB, Anderson BO, Bonaccio E, Buys S, Daly MB, Dempsey PJ, Farrar WB, Fleming I, Garber JE, Harris RE, Heerdt AS, Helvie M, Huff JG, Khakpour N, Khan SA, Krontiras H, Lyman G, Rafferty E, Shaw S, Smith ML, Tsangaris TN, Williams C, Yankeelov T: NCCN clinical practice guidelines in oncology: breast cancer screening and diagnosis. J Natl Compr Canc Netw 2009;7:1060-1096.

3 Goldhirsch A, Glick JH, Gelber RD, Coates AS, Thurlimann B, Senn HJ: Meeting highlights: international expert consensus on the primary therapy of early breast cancer 2005. Ann Oncol 2005;18: 1569-1583.
4 Kreienberg R, Kopp I, Albert U, Bartsch HH, Beckmann MW, Berg D, Bick U, du Bois A, Budach W, Dunst J, Engel J, Ernst B, Geraedts M, Henscher U, Hölzel D, Jackisch C, König K, Kreipe H, Kühn T, Lebeau A, Leinung S, Link H, Lück HJ, Madjar H, Maiwald A, Maiwald G, Marschner N, Marx M, von Minckwitz G, NaßGriegoleit I, Possinger K, Reiter A, Sauerbrei W, Schlake W, Schmutzler R, Schreer I, Schulte H, Schulz KD, Souchon R, Thomssen C, Untch M, Wagner U, Weis J, Zemmler T: Deutsche Krebsgesellschaft (ed): Interdisciplinary S3 Guidelines for the Diagnosis, Treatment and Follow-Up Care of Breast Cancer. W. Zuckschwerdt Verlag GmbH, Munich, 2008.
5 Kantelhardt EJ, Thomssen C: German Recommendations for Diagnosis and Treatment of Breast Cancer 2008. What is new from the Breast Commission of the German Gynaecological Oncology Working Group (AGO)? Breast Care (Basel) 2008;3:93-99.

6 Varga D, Wischnewsky M, Atassi Z, Wolters R, Geyer V, Strunz K, Kreienberg R, Woeckel A: Does guideline-adherent therapy improve the outcome for early-onset breast cancer patients? Oncology 2010;79:189-195.

7 Geller BM, Kerlikowske K, Carney PA, Abraham LA, Yankaskas BC, Taplin SH, Ballard-Barbash R, Dignan MB, Rosenberg R, Urban N, Barlow WE: Mammography surveillance following breast cancer. Breast Cancer Res Treat 2003;81:107-115. 
8 Veit C, Bauer J, Döbler K, Fischer B: Qualität sichtbar machen. BQS-Qualitätsreport 2008; in Gemeinsamer Bundesausschuss (ed). Schotte, Krefeld, 2008.

9 Blamey RW, Cataliotti L: EUSOMA accreditation of breast units. Eur J Cancer 2006;42:1331-1337.

10 Del Turco MR, Ponti A, Bick U, Biganzoli L, Cserni G, Cutuli B, Decker T, Dietel M, Gentilini O, Kuehn T, Mano MP, Mantellini P, Marotti L, Poortmans P, Rank F, Roe H, Scaffidi E, van der Hage JA, Viale G, Wells C, WelnickaJaskiewicz M, Wengstom Y, Cataliotti L: Quality indicators in breast cancer care. Eur J Cancer 2010;46:2344-2356.

11 Brucker SY, Bamberg M, Jonat W, Beckmann MW, Kammerle A, Kreienberg R, Wallwiener D Certification of breast centres in Germany: proof of concept for a prototypical example of quality assurance in multidisciplinary cancer care. BMC Cancer 2009;9:228.

12 Brucker SY, Schumacher C, Sohn C, Rezai M, Bamberg M, Wallwiener D: Benchmarking the quality of breast cancer care in a nationwide voluntary system: the first five-year results (2003-2007) from Germany as a proof of concept. BMC Cancer 2008;8:358.

13 Scharl A, Gohring UJ: Does center volume correlate with survival from breast cancer? Breast Care (Basel) 2009;4:237-244.
14 Wockel A, Kurzeder C, Geyer V, Novasphenny I, Wolters R, Wischnewsky M, Kreienberg R, Varga D: Effects of guideline adherence in primary breast cancer - a 5-year multi-center cohort study of 3,976 patients. Breast 2010;19:120-127.

15 Wockel A, Varga D, Atassi Z, Kurzeder C, Wolters R, Wischnewsky M, Wulff C, Kreienberg R: Impact of guideline conformity on breast cancer therapy: results of a 13-year retrospective cohort study. Onkologie 2010;33:21-28.

16 Beckmann MW: Projektgruppe Mamma- und Genitalkarzinome; in Beckmann MW, Petsch S (eds): Quality Report 2009, Cancer in Middle Franconia 1998-2007. Erlangen, Tumorzentrum der Universität Erlangen-Nürnberg, 2009, pp. 123-131.

17 Sobin H, Gospodarowicz MK, Wittekind C (eds): TNM Classification of Malignant Tumours (UICC International Union Against Cancer). New York, NY, Wiley \& Sons Ltd., 2009.

18 Yun YH, Park SM, Noh DY, Nam SJ, Ahn SH, Park BW, Lee ES: Trends in breast cancer treatment in Korea and impact of compliance with consensus recommendations on survival. Breast Cancer Res Treat 2007;106:245-253.

19 McCarthy M, Datta P, Khachatryan A, Coleman MP, Rachet B: Would compliance with cancer care standards improve survival for breast, colorectal and lung cancers? J Epidemiol Community Health 2008;62:650-654.
20 Wilks JA, Liebig C, Tasleem SH, Haderxhanaj K, Lee L, Farrow B, Awad S, Berger D, Albo D: Rectal cancer patients benefit from implementation of a dedicated colorectal cancer center in a Veterans Affairs Medical Center. Am J Surg 2009; 198:100-104.

21 Stiller CA: Centralised treatment, entry to trials and survival. Br J Cancer 1994;70:352-362.

22 Braunholtz DA, Edwards SJ, Lilford RJ: Are randomized clinical trials good for us (in the short term)? Evidence for a 'trial effect'. J Clin Epidemiol 2001;54:217-224

23 Hebert-Croteau N, Brisson J, Lemaire J, Latreille J: The benefit of participating to clinical research. Breast Cancer Res Treat 2005;91:279-281.

24 Peppercorn JM, Weeks JC, Cook EF, Joffe S: Comparison of outcomes in cancer patients treated within and outside clinical trials: conceptual framework and structured review. Lancet 2004;363:263270 .

25 Landsberger HA: Hawthorne revisited: management and the worker: its critics, and developments in human relations in industry; in: Cornell Studies in Industrial and Labor Relations. Ithaca, Cornell University, 1958.

26 Lux MP, Fasching PA, Bani MR, Schrauder M, Loehberg CR, Oppelt P, Hildebrandt T, Grun AH, Beckmann MW, Goecke TW: Marketing of breast and perinatal centers - are patients familiar with the product 'Specialized Centers and Certification'? Geburtsh Frauenheilk 2009;69:321-327. 